\section{Genetic Interactions of Pillar and Weeping Peach Genotypes}

\author{
Dennis J. Werner and Jose X. Chaparro ${ }^{1}$ \\ Department of Horticultural Science, Box 7609, North Carolina State University, \\ Raleigh, NC 27695-7609
}

Additional index words. Prunus persica, growth habit, tree architecture, peach breeding, epistasis

\begin{abstract}
Genetic interaction of the pillar (PI) and weeping (WE) growth habit genotypes was investigated in peach [Prunus persica $\left(\mathrm{L}\right.$.) Batsch]. Data from $\mathrm{F}_{2}, \mathbf{B C}_{1 \mathrm{P}}$, and $\mathbf{B C}_{1 \mathrm{P}}$ families showed that PI (brbr) was epistatic to the expression of WE ( $p l p l)$. A unique growth habit not previously described in peach, and referred to as arching (AR), was recovered in the $\mathrm{F}_{2}$ family. Arching trees showed an upright phenotype similar to $\mathrm{Brbr}$ heterozygotes, but had a distinct curvature in the developing shoots. Progeny testing of AR trees revealed their genotype is Brbrplpl.
\end{abstract}

Peach is a model organism for the genetic and physiological study of growth habit and architecture in woody plants. Several genes influencing tree architecture have been identified and described in peach [Prunus persica (L.) Batsch] (Scorza et al., 2002). Inheritance of both the pillar (PI) and weeping (WE) growth habits has been reported. The PI growth habit, also designated as broomy in the literature, is controlled by a single recessive gene designated $b r$ (Yamazaki et al., 1987). Incomplete dominance at the $b r$ locus allows heterozygotes to be distinguished from both homozygous classes in most genetic backgrounds, having an intermediate architecture referred to as upright (UP). Weeping growth habit is also controlled by a single recessive gene, designated $p l$ (Monet et al., 1988, Yamazaki et al., 1987). Both of these reports proposed dominant gene action at the $P l$ locus, but Bassi and Rizzo (2000) noted that heterozygotes can be discerned from homozygotes, suggesting incomplete dominance. Limited studies have been conducted examining the interaction of the $b r$ and $p l$ genes. Yamazaki et al. (1987) reported that $F_{1}$ progeny derived from crosses between PI and WE parents produced normal progeny, while Scorza et al. (2002) reported that crosses between WE and PI produced plants with upright architecture. Limited $\mathrm{F}_{2}$ family data was provided by Yamazaki et al., but no genetic model was proposed to explain the observed phenotypic ratios. Bassi and Rizzo (2000) described the branch angles on $F_{1}$ trees

Received for publication 28 May 2004. Accepted for publication 6 Aug. 2004. Thanks to Steve Worthington and Layne Snelling for technical assistance. Appreciation is extended to the staff of the Sandhills Research Station, Jackson Springs, N.C., for assistance with field plot management. Research supported by funds provided by the North Carolina Agricultural Research Service (NCARS) and North Carolina Foundation Seed Producers, Inc. (NCFSP). Figure 1 photographs taken by Herman Lankford, Dept. of Communication Services, North Carolina State University.

${ }^{1}$ Current address: Department of Horticultural Science, Fifield Hall, University of Florida, Gainesville, FL 32611-0690. derived from crosses between WE and PI forms. In this study, we describe the interaction of the $b r$ and $p l$ genes using segregation data obtained from $\mathrm{P}_{1}, \mathrm{P}_{2}, \mathrm{~F}_{1}, \mathrm{~F}_{2}, \mathrm{BC}_{1 \mathrm{P} 1}, \mathrm{BC}_{1 \mathrm{P} 2}$, and $\mathrm{F}_{3}$ families. We further describe the recovery of an architectural form not described previously in peach, designated archer (AR), and propose a genotype for this new growth habit.

\section{Materials and Methods}

Parental germplasm and hybridization for development of $F_{1}$ families. Interaction of the $b r$ and $p l$ genes was tested in numerous families derived from hybridization between 'Pillar' $(b r b r) \times$ 'White Glory' $(p l p l)$. The source of 'Pillar' used in this study was initially obtained from L. F. Hough at Rutgers University, New Brunswick, NJ, representing material originally imported from Japan. According to Scorza et al. (2002), this material obtained by Hough appears to be similar or identical to the Japanese cultivar, 'Hoki'. 'White Glory' is a weeping ornamental nectarine derived from 'S37' (Werner et al., 1985). 'Pillar' was used as the female parent in the original hybridization. The hybridization method was as described by Scorza and Sherman (1996).

Development of $P_{1}, P_{2}, B C_{l P l}, B C_{1 P 2}, F_{2}$, and $F_{3}$ families. The $\mathrm{BC}_{1 \mathrm{P} 1}$ and $\mathrm{BC}_{1 \mathrm{P} 2}$ families were generated using the same $\mathrm{F}_{1}$ hybrid plant as the female parent. The $\mathrm{P}_{1}, \mathrm{P}_{2}, \mathrm{~F}_{2}$, and $\mathrm{F}_{3}$ families were obtained through self-pollination by covering trees with parachutes from prebloom until petal fall (Werner and Cain, 1985). Three $F$ trees were self-pollinated for development of $\mathrm{F}_{2}$ families. A sample of plants exhibiting the new growth form classified as AR were self-pollinated to produce $\mathrm{F}_{3}$ families to determine the genotype of AR trees.

Seed germination, field culture, and growth habit evaluation. In all cases, fruit from controlled hybridizations or self-pollinations were harvested at the firm-ripe stage. Seed were removed from the endocarp and immediately stratified (moist prechilled) at $4{ }^{\circ} \mathrm{C}$ until visible radicle emergence, planted in a sterile soilless mix, and grown in the greenhouse for 3 to 4 months before transplanting to the field. Plants were established in the field in the spring at a spacing of $0.6 \mathrm{~m}$ within rows and $6.7 \mathrm{~m}$ between rows. Growth habit was evaluated by two observers in the dormant season following two seasons of growth. Based on field observation, trees were placed into one of five phenotypic classes: standard (ST), upright (heterozygous PI, UP), pillar (PI), weeping (WE), and arching (AR). The AR phenotype has not been described previously in the literature, and is discussed below. Proposed phenotypes and genotypes of parental, $\mathrm{F}_{1}, \mathrm{BC}_{1 \mathrm{P} 1}, \mathrm{BC}_{1 \mathrm{P} 2}, \mathrm{~F}_{2}$, and $\mathrm{F}_{3}$ trees used in this study are presented in Table 1.

Data analysis. Segregation data for growth habit phenotypes in $\mathrm{F}_{2}, \mathrm{BC}_{1 \mathrm{P} 1}, \mathrm{BC}_{1 \mathrm{P} 2}$, and $\mathrm{F}_{3}$ families was tested for departures from the expected Mendelian ratios using the chi-square test. Since three full-sib $F_{2}$ families were used in this study, data from each family were tested for departure from homogeneity. The homogeneity chi-square was nonsignificant, so data from all three $\mathrm{F}_{2}$ families was combined prior to analysis. Initial observation of $\mathrm{F}_{2}$ segregation ratios suggested recessive epistatic interaction between the $b r$ and $p l$ genes so a Mendelian model based on recessive epistasis was tested to explain the observed segregations.

\section{Results and Discussion}

Self-pollination of the PI and WE parents confirmed that each was homozygous for the $b r$ and $p l$ alleles, respectively (Table 2). The three $F_{1}$ trees derived from hybridization of these parents showed a growth habit similar to the UP phenotype expected of $\mathrm{Brbr}$ trees (Scorza et al, 2002), however a clear distinction from the ST growth habit was difficult. Similarly, conclusive distinction of $\mathrm{Brbr}$ (UP)

Table 1. Parental phenotypes and genotypes, an genotypes and predicted phenotypes of $\mathrm{F}_{1}, \mathrm{BC}_{1 \mathrm{P} 1}$, $\mathrm{BC}_{1 \mathrm{P} 2}, \mathrm{~F}_{2}$, and $\mathrm{F}_{3}$ progeny.

\begin{tabular}{|c|c|c|}
\hline Parental & $\begin{array}{l}\left(\mathrm{P}_{1}\right) \times \\
\text { Pillar }(\mathrm{PI}) \times \\
\text { brbrPlPl }\end{array}$ & $\begin{array}{l}\left(\mathrm{P}_{2}\right) \\
\text { White Glory (WE) } \\
\text { BrBrplpl }\end{array}$ \\
\hline $\mathrm{F}_{1}$ & BrbrPlpl (UP) & \\
\hline $\mathrm{BC}_{1 \mathrm{P} 1}$ & $\begin{array}{l}\text { BrbrPlPl (UP) } \\
\text { BrbrPlpl (UP) } \\
\text { brbrPlPl (PI) } \\
\text { brbrPlpl (PI) }\end{array}$ & \\
\hline $\mathrm{BC}_{1 \mathrm{P} 2}$ & $\begin{array}{l}\text { BrBrPlpl (ST) } \\
\text { BrBrplpl (WE) } \\
\text { BrbrPlpl (UP) } \\
\text { Brbrplpl (AR) }\end{array}$ & \\
\hline $\mathrm{F}_{2}$ & $\begin{array}{l}\text { BrBrPlPl (ST) } \\
\text { BrBrPlpl (ST) } \\
\text { BrBrplpl (WE) } \\
\text { BrbrPlPl (UP) } \\
\text { BrbrPlpl (UP) } \\
\text { Brbrplpl (AR) } \\
\text { brbrPlPl (PI) } \\
\text { brbrPlpl (PI) } \\
\text { brbrplpl (PI) }\end{array}$ & \\
\hline $\mathrm{F}_{3}$ [self & $\begin{array}{l}\text { brplpl (AR phe } \\
\text { BrBrplpl (WE) } \\
\text { Brbrplpl (AR) } \\
\text { brbrplpl (PI) }\end{array}$ & otype)] \\
\hline
\end{tabular}




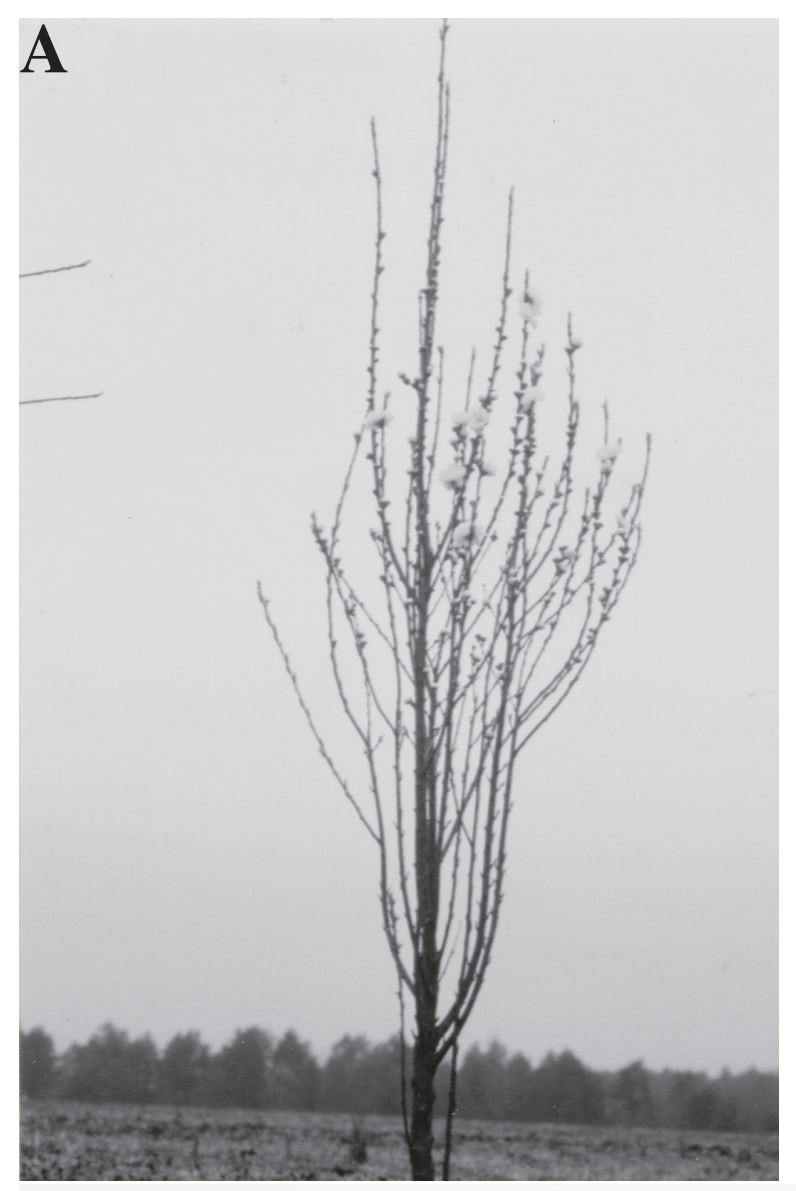

$\mathbf{C}$
B

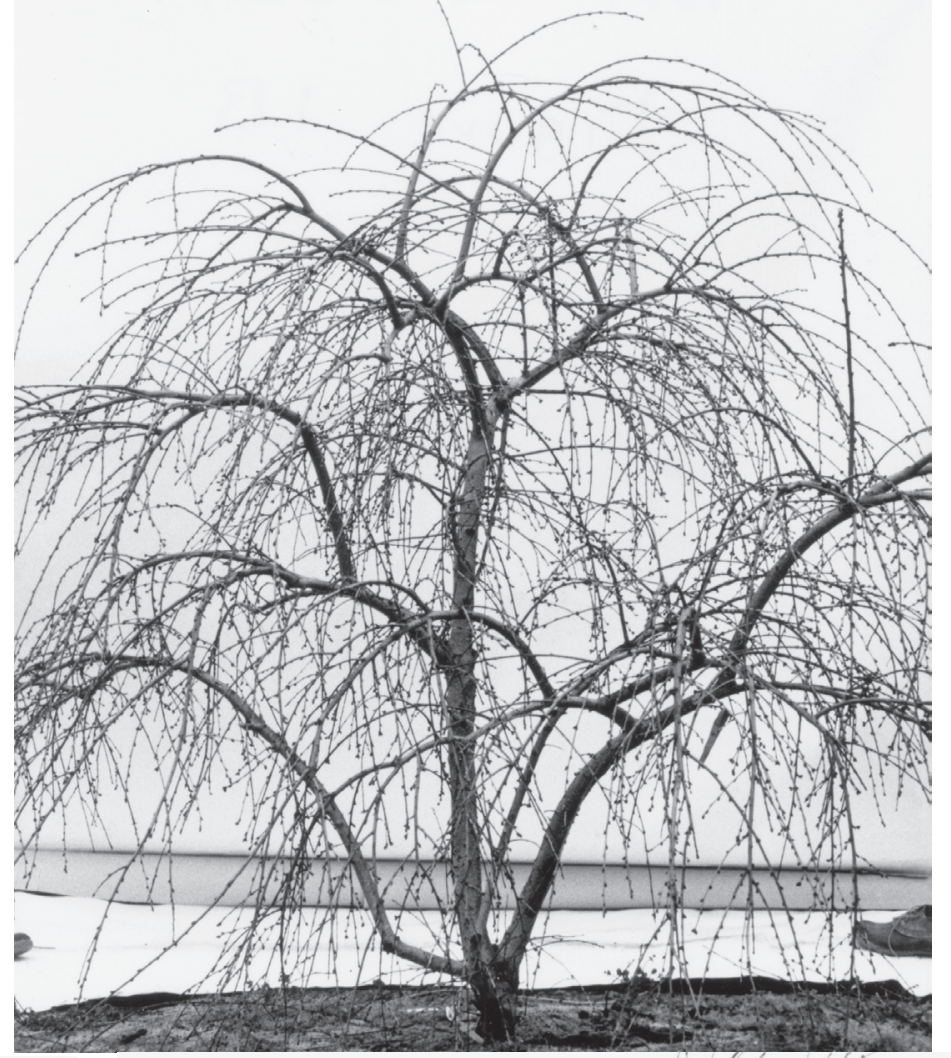

D

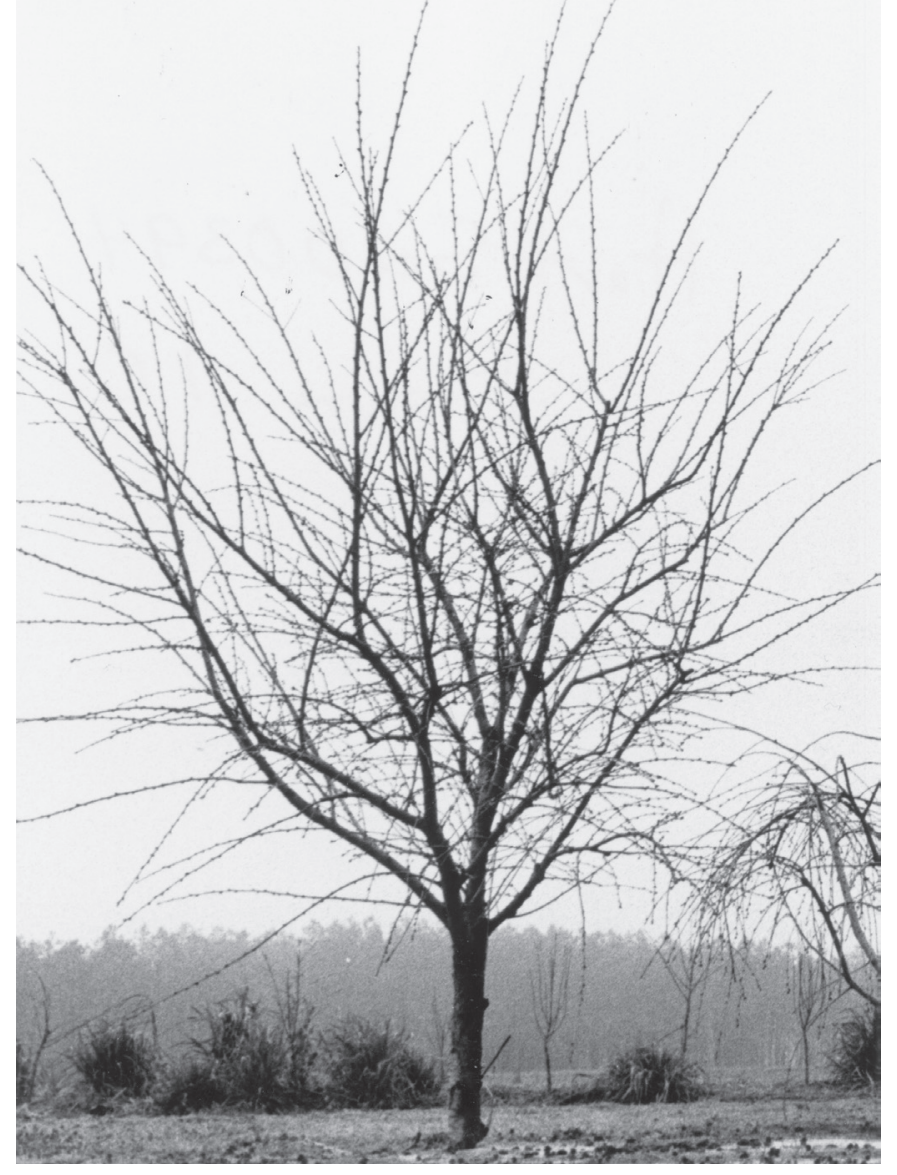

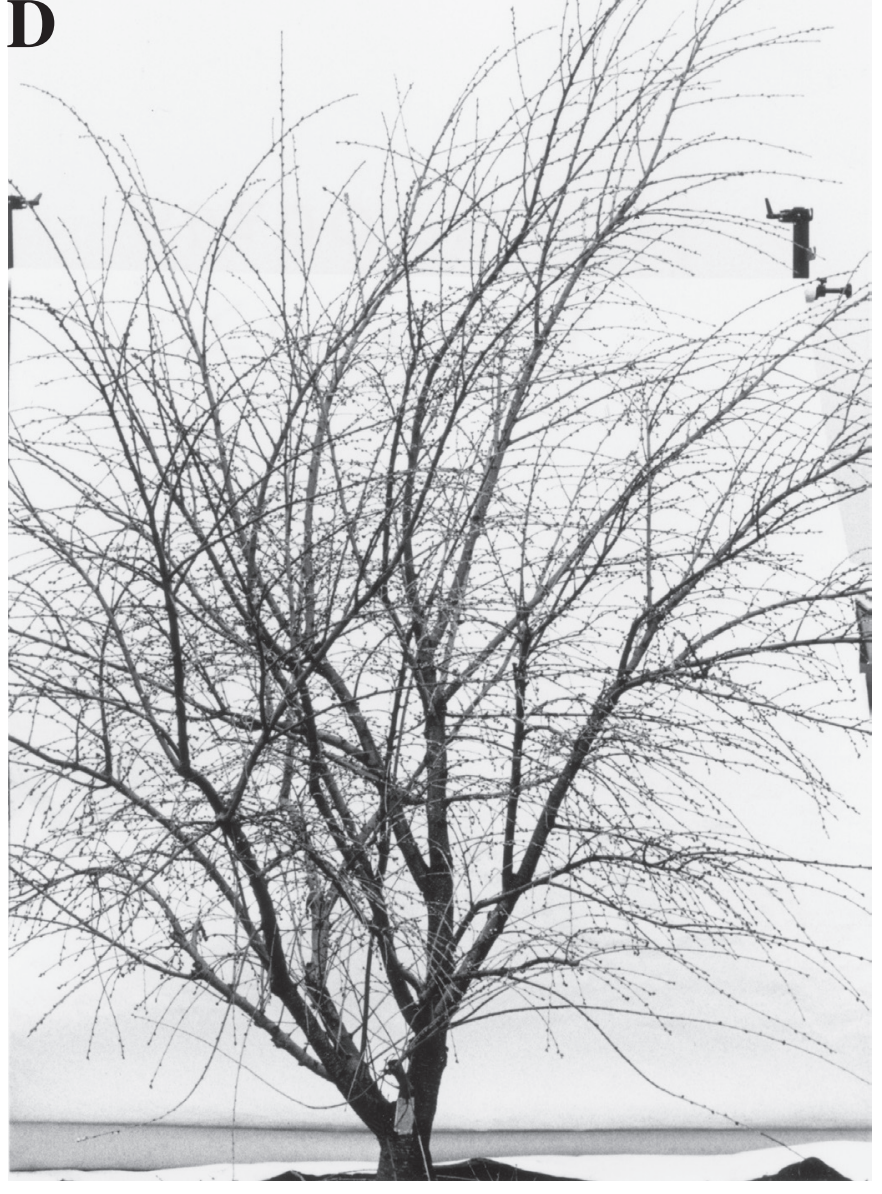

Fig. 1. Minimally pruned (lower branches removed) $\mathrm{F}_{2}$ peach seedlings, 4 years in the field (pillar in A only 2 years old). (A) Pillar (PI) phenotype, (B) weeping (WE) phenotype, (C) upright (UP) phenotype, and (D) archer (AR) phenotype. 
Table 2. Segregation for peach tree growth habit in $\mathrm{P}_{1}, \mathrm{P}_{2}, \mathrm{~F}_{1}, \mathrm{~F}_{2}, \mathrm{BC}_{1 \mathrm{P} 1}, \mathrm{BC}_{1 \mathrm{P2}}$, and $\mathrm{F}_{3}$ families derived from the parents 'Pillar' (PI) and 'White Glory' (WG).

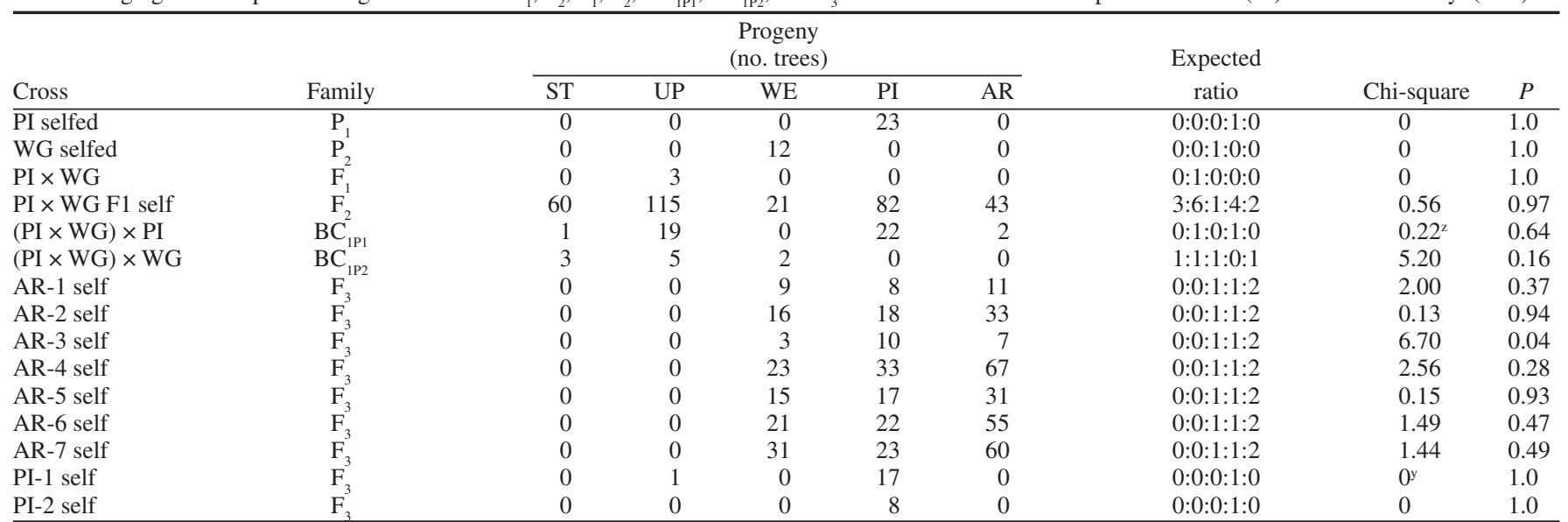

${ }^{2}$ Recovery of one ST tree and two AR trees in this family was unexpected and inconsistent with the proposed recessive epistasis genetic model, but could have arisen as a consequence of accidental self-pollination. These three trees were not used in calculation of chi-square.

${ }^{y}$ Recovery of the one UP tree in this family was unexpected, but could have arisen as a consequence of accidental self-pollination. This tree was not used in calculation of chi-square.

individuals from $\mathrm{ST}$ homozygous $(\mathrm{Br} B r)$ individuals in $\mathrm{F}_{2}$ and $\mathrm{BC}$ families was sometimes difficult. In contrast, pillar (PI) and weeping (WE) trees could be unambiguously classified in segregating families.

A distinctly different and novel phenotype was identified in the $\mathrm{F}_{2}$ family. Trees demonstrating this phenotype showed upright to semi-upright branch angles between the main trunk and primary branches, suggestive of heterozygosity at the $\mathrm{Br}$ locus (UP). However, unlike normal upright individuals, these trees showed a semi-weeping appearance manifested as a distinct curvature in the developing shoots. We classified these trees as arching (AR). Figure 1 shows a typical AR tree compared to UP, WE, and PI trees.

The $\mathrm{F}_{2}$ data (Table 2) showed an excellent fit to a recessive epistasis model, with $b r b r$ being epistatic to expression of $p l p l$. Hence, the weeping phenotype is not expressed in a homozygous brbrbackground. Backcross data was in general agreement with the $\mathrm{F}_{2}$ data. Both $\mathrm{BC}$ families supported the recessive epistasis model in that no WE or PI individuals were recovered in the $\mathrm{BC}_{1 \mathrm{P} 1}$ or $\mathrm{BC}_{2 \mathrm{P} 2}$ families, respectively. The $\mathrm{BC}_{1 \mathrm{P} 1}$ family showed a good fit to the expected 1:1 (PI:ST) ratio. The presence of two AR trees in this family was unexpected and cannot be explained by the model, but could be due to accidental self-pollination. The $\mathrm{BC}_{1 \mathrm{P} 2}$ segregation fit the expected 1:1 (ST: $\mathrm{WE})$ ratio, but showed a deficiency in the WE class. However, population size in this family was small.

Based on the epistatic interaction observed between the $b r$ and $p l$ genes and the observed frequency of $A R$ trees recovered in the $F_{2}$ family, we hypothesized that trees showing the AR phenotype had a genotype of Brbrplpl. If so, $\mathrm{F}_{3}$ families derived from self-pollination of AR trees would produce PI, AR, and WE offspring in an expected ratio of 1:2:1, respectively. Accordingly, seven AR trees were selected at random from the $\mathrm{F}_{2}$ family, selfed, and progeny were evaluated. Six of the seven families fit the expected 1:2:1 (PI:AR: WE) test ratio. Archer family \#3 showed the poorest fit, having a deficiency in the number of AR individuals, probably resulting from the small population size of this $\mathrm{F}_{3}$ family. These results provide strong support that trees classified as AR are of genotype Brbrplpl, and that the epistatic effect of the $b r$ allele on the expression of weeping is operative even in Brbr heterozygotes, although not to the extent found in $b r b r$ homozygotes.

Scorza et al. (2002) reported the production of distinct new tree forms through recombining genes controlling the dwarf (DW), compact
(CT), and PI growth forms. In this study, we demonstrate the production of a novel growth form called archer previously unreported in peach, through the combination of the $b r$ and $p l$ genes. This form, demonstrating upright branch angles near the juncture between the lateral branch and main trunk, but showing a distinct curvature in the developing shoots, may have potential for commercial production. In agreement with Scorza et al. (2002), this study confirms the plasticity in peach tree growth, and the potential for developing novel growth forms through combination of different genes controlling growth habit.

\section{Literature Cited}

Bassi, D. and M. Rizzo. 2000. Peach breeding for growth habit. Acta Hort. 538:411-414.

Monet, R., Y. Bastard, and B. Gibault. 1988. Etude genetique du caractere "port pleureur" chez pecher. Agronomie 8:127-132.

Scorza, R., D. Bassi, and A. Liverani. 2002. Genetic interactions of pillar (columnar), compact, and dwarf peach tree genotypes. J. Amer. Soc. Hort. Sci. 127:254-261.

Werner, D.J. and D.W. Cain. 1985. Cages for protection of tree fruit hybridizations. HortScience 20:450-451.

Yamazaki, K., M. Okabe, and E. Takahashi. 1987. Inheritance of some characteristics and breeding of new hybrids in flowering peaches (in Japanese). Kanagawa Enshi Kempo 34:46-53. 